\title{
NEW MANUAL AND DIGITAL EXPLORATION IN SURFACE TEXTILE DESIGN: A SUPERUSER APPROACH IN DESIGN EDUCATION
}

\author{
Wenche LYCHE and Pernille ØVERJORDET \\ Department of Product Design, Faculty of Technology, Art and Design, Oslo Metropolitan \\ University, Norway
}

\section{ABSTRACT}

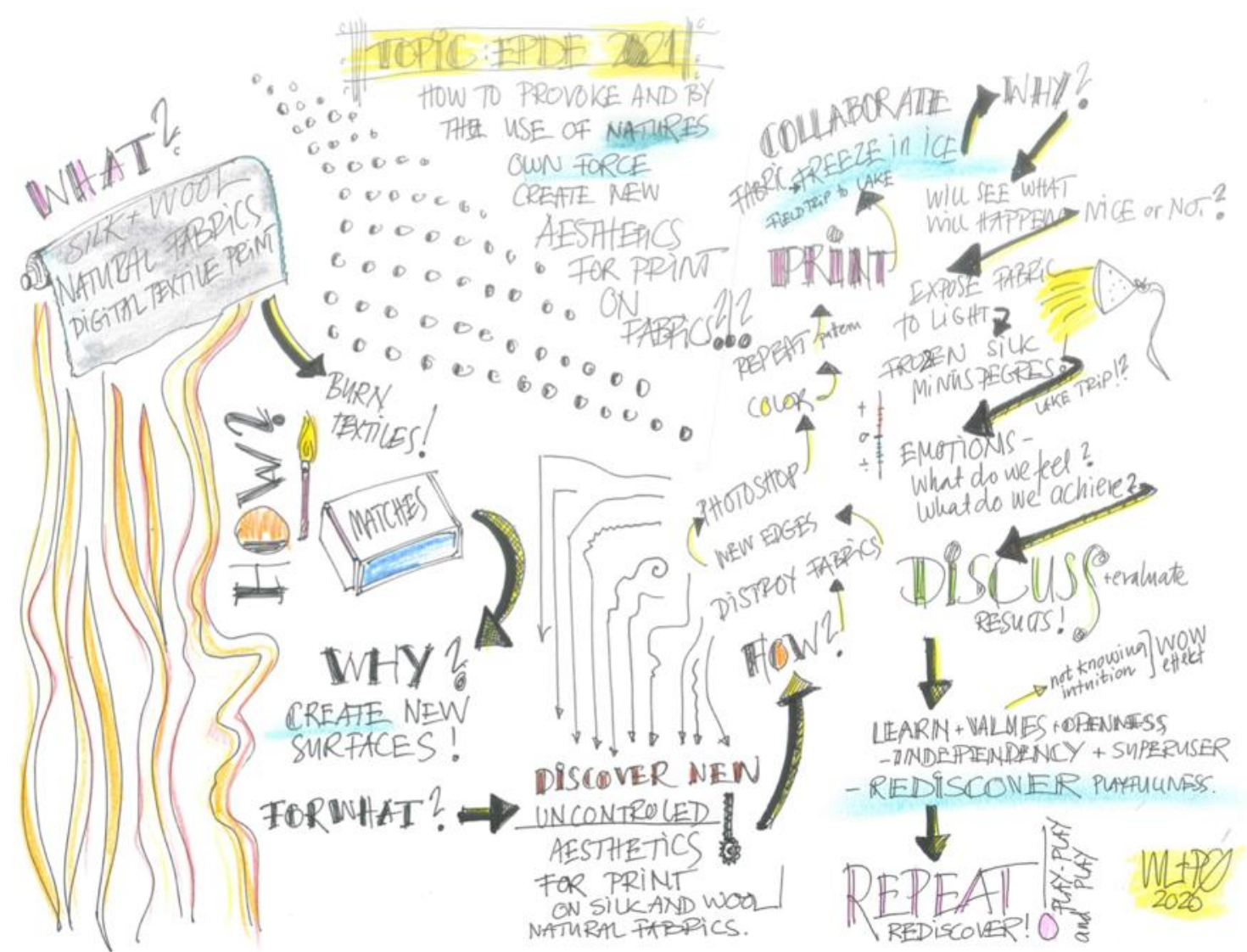

Manual exploration versus digital exploration is now adays part of students learning processes and there is a growing need in society to understand the relationships between manually created surfaces and creativity based on new technology. Still manual exploration is necessary to understand and cherish he unexpected that can be understood, transformed, discovered and create new value, for product design students and the product. This paper will take into consideration several aspects of learning during several workshops. One workshop was a direct change and improvised workshop due to Covid and took place outside in minus degrees. One approach is instructors showing creative ways to find new surfaces through exploratory surface design methods exposing students to open result design processes. Another approach is students working more independently as superusers to explore their own surfaces. A third approach is evaluation and collaboration between instructor and student in digital exploration introducing the student to digital textile printing, textile science, sustainability and at the same time introducing students to academic writing. The digital textile printing was related to exploring surface design and then transformed into patterns for digital print. In this qualitative study it is documented what 
the hand can create, intuitively with textiles, provoking and understanding the aesthetics of surface textile design by using force of nature such as low minus degrees, flames, light exposure combined with digital textile printing. Core values will be based on natural fibres in printing on wool and silk to enhance quality and ensure a stronger connection between product and consumer. The discussion evolves around the value of emotional design in new technology and Donald Normans concepts in "Design for everyday things". The consumers ability to connect to such aesthetic design is explored in relation to social sustainability.

Keywords: Surface textile patterns, aesthetics influenced by the force of nature, communities of practice, playfulness, emotional design

\section{INTRODUCTION: EMOTIONAL DESIGN AND PRODUCTS}

This paper is discussing the importance of exploration to find unexpected aesthetical motifs for textiles during workshops. The value of exploratory manual methods in design processes is a valuable asset for design students in an ever more digital world. During workshops tutor and students work together to discover how to create, collaborate and discuss how emotional design connects to the user and product and hopefully be more sustainable [1].

\section{ACTION DRIVEN WORKSHOP}

Due to Covid and closed campus, we decided to improvise a workshop outside to explore the Norwegian winters and experience how 14 minus degrees will change the appearance and performance of printed wool and silk.

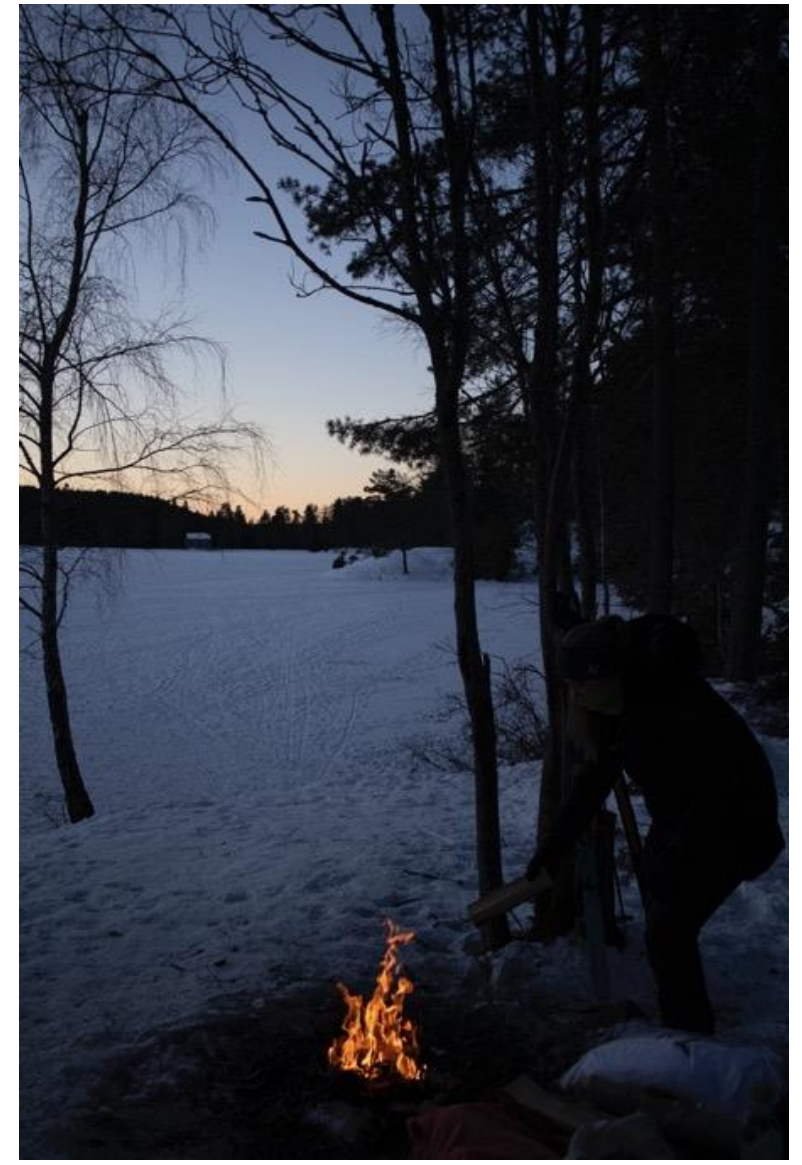

Figure 2: Making fire in sunrise

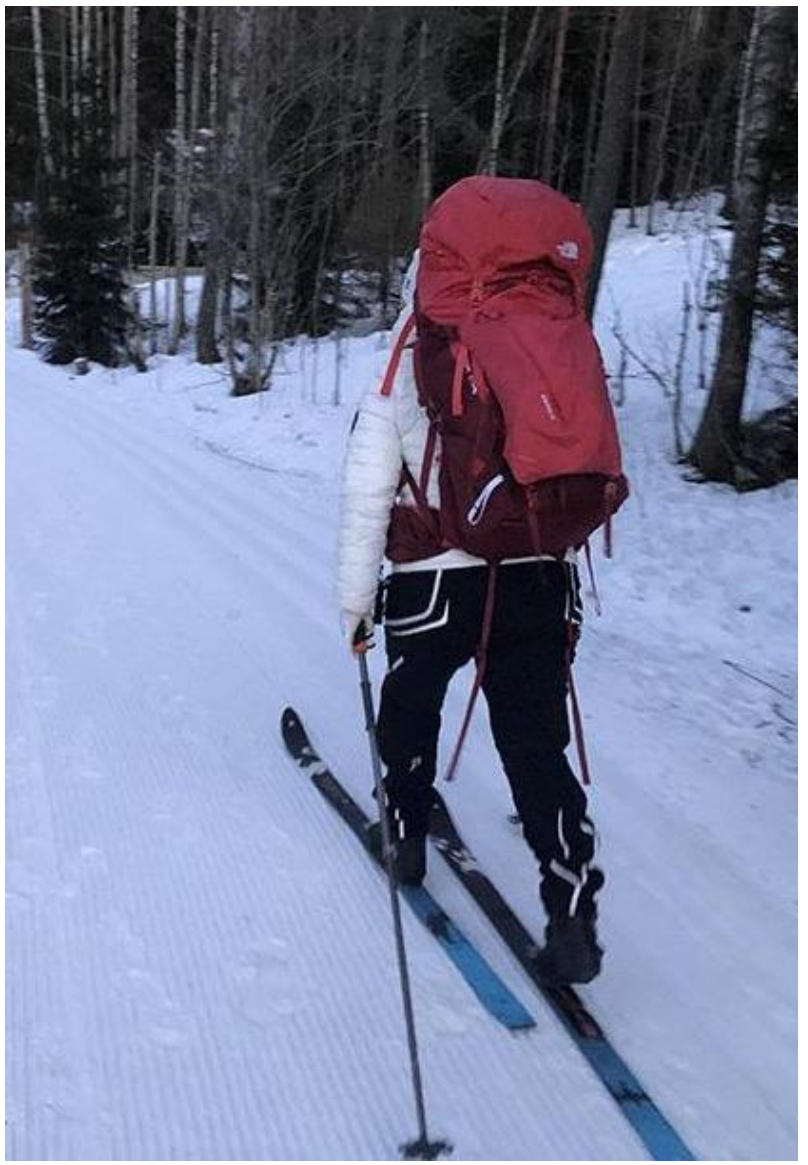

Figure 1: Skiing into the forest 


\subsection{Workshop in the wilderness- frozen textiles}

The student was introduced to hanging textiles in the trees, after having dipped the textile in cold water. It froze quickly, and we displayed the textiles standing up. We asked ourselves: what we would get out of the cold winter morning? What would happen with the textiles? Will it give us new insight to creative ideas and support openness we need in design processes?

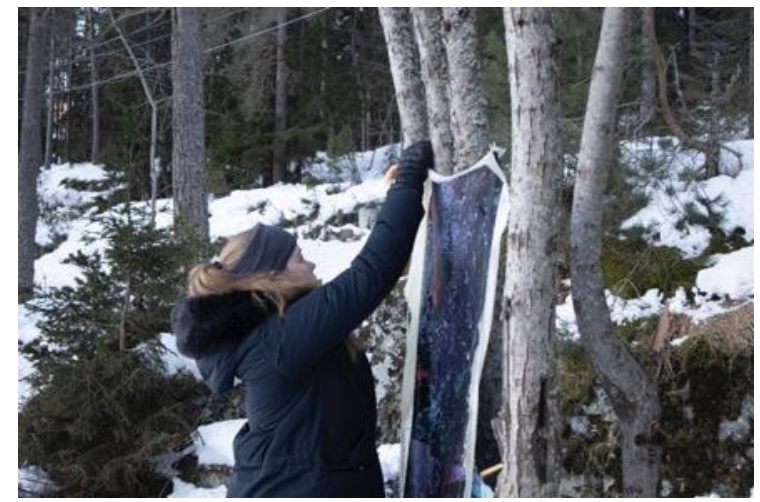

Figure 3: Wool fabric in the trees

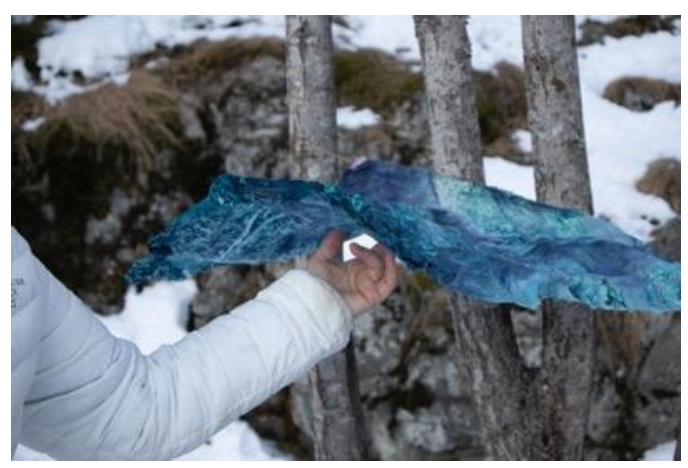

Figure 5: Printed wet silk froze in 20 seconds in -14 degrees

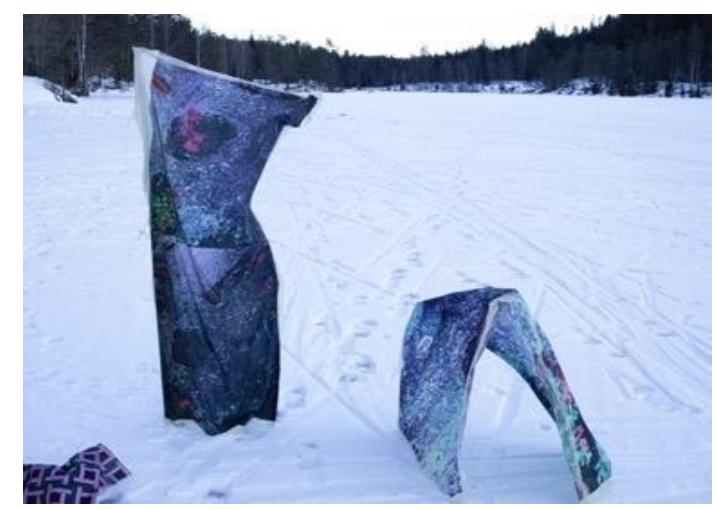

Figure 7: Standing wool

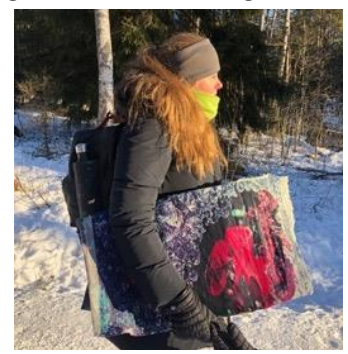

Figure 9: Frozen wool inspired to new products such as,

portefolios or book covers (1).

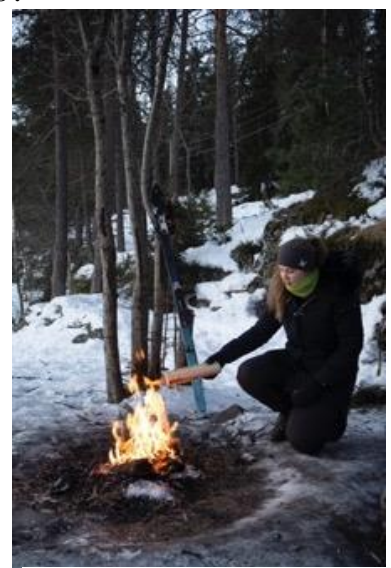

Figure 4: light up a fire

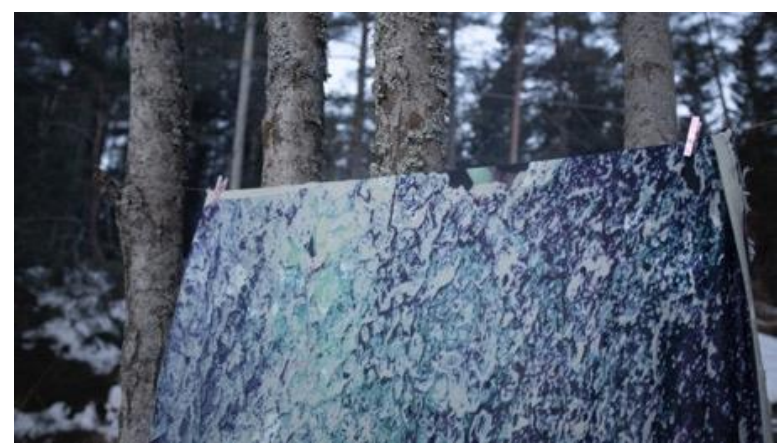

Figure 6: Wet wool froze in less than a minute

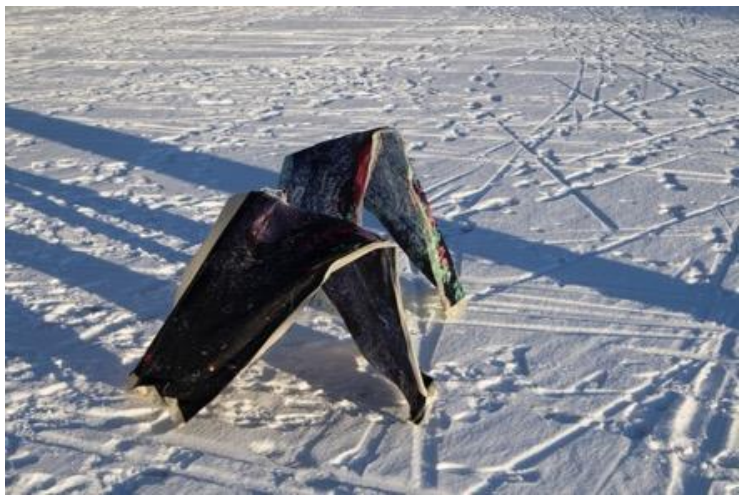

Figure 8: Sunrise collapsed the textile

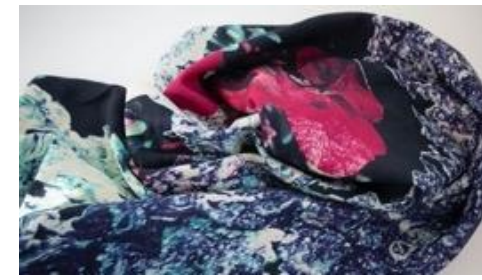
Figure 10: Soft as normal up

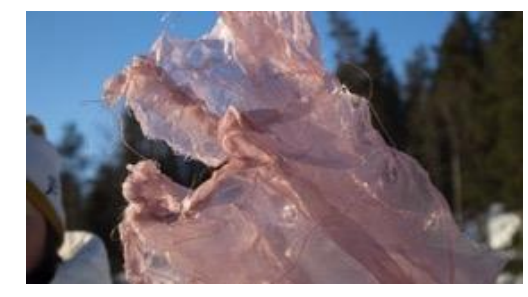

Figure 11: Organza silk standing up 


\subsection{Workshop burning silk and wool}

We provoke textiles manually by using fire to get out of the comfort zone and engage in "unleashing the creative potential within ourselves" [3].

Our $2^{\text {nd }}$ year Bachelor student was encouraged to burn silk, wool, and synthetic fabrics to experience herself. Then take pictures of surfaces, isolate interesting areas and develop further in Photoshop. Coincidences and uncontrollable "errors" can be used in aesthetic design processes [2]. Knowing what to do but allowing to explore the unfamiliar, Don Normans book Design Of Everyday Things discussing cultural conventions and allowances.

Surfaces on textile can be of repeated patterns and single motifs for illustrations or basis for another repeated pattern. Translated + Glide reflection is a technique in repeat pattern and created flow to the pattern. (Fig 15.)

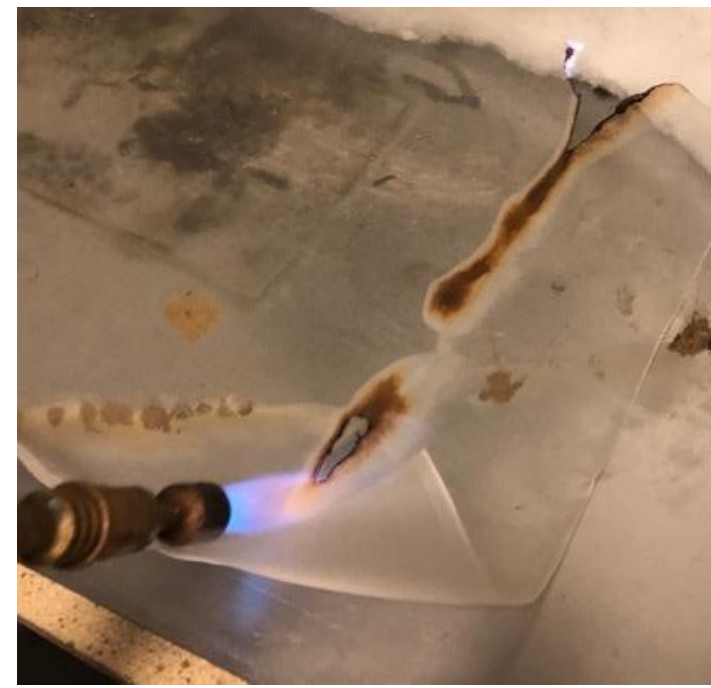

Figure 12: Silk organza exposed to flames

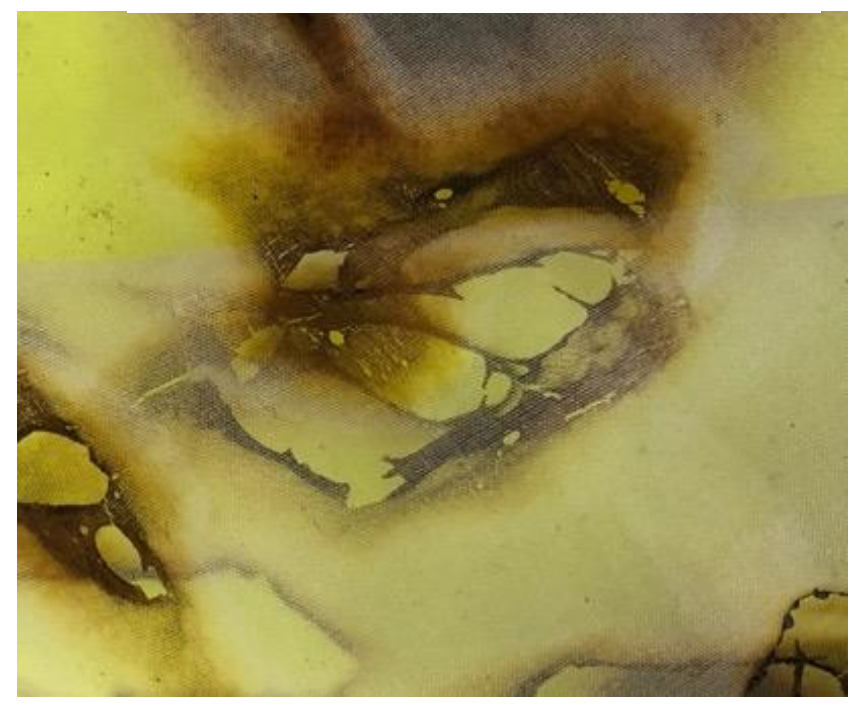

Figure 14: Isolated area from Fig 13.

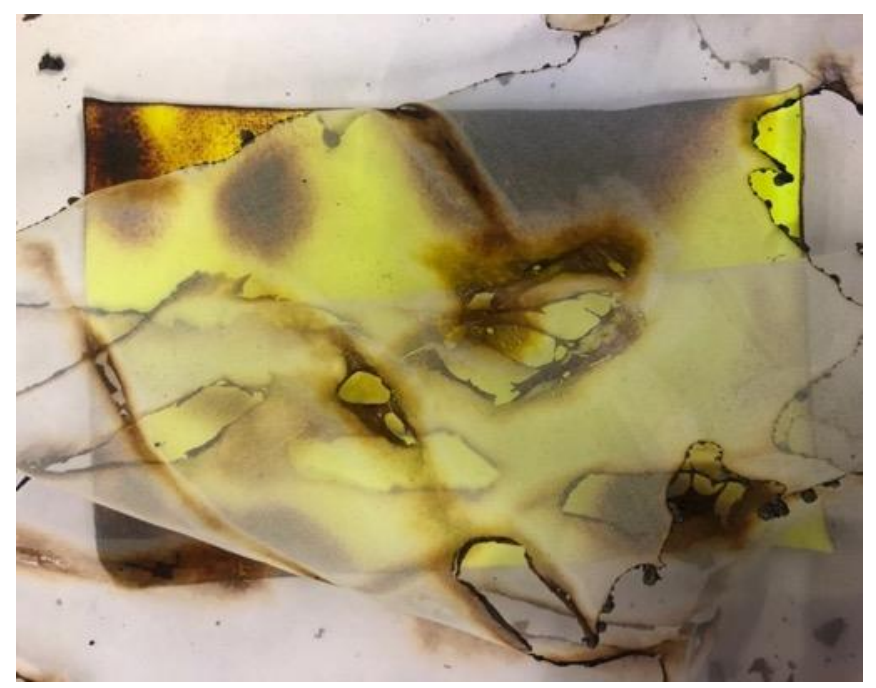

Figure 13: Plastic and organza

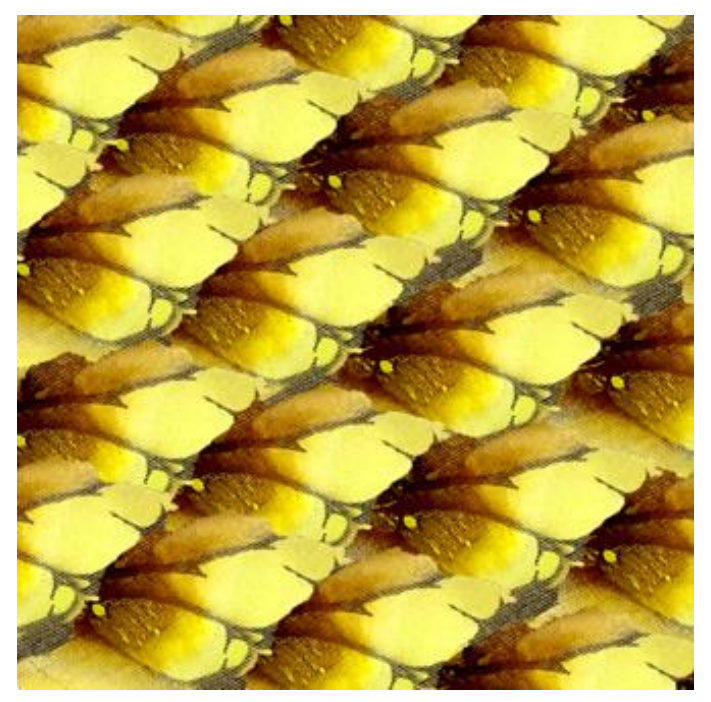

Figure 15: Repeated pattern 


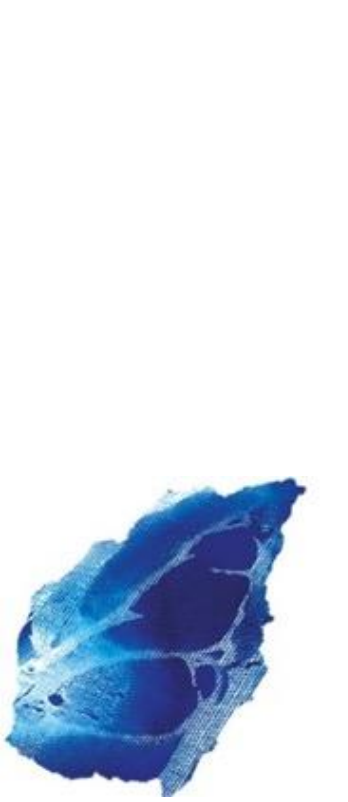

Figure 16: Isolated area
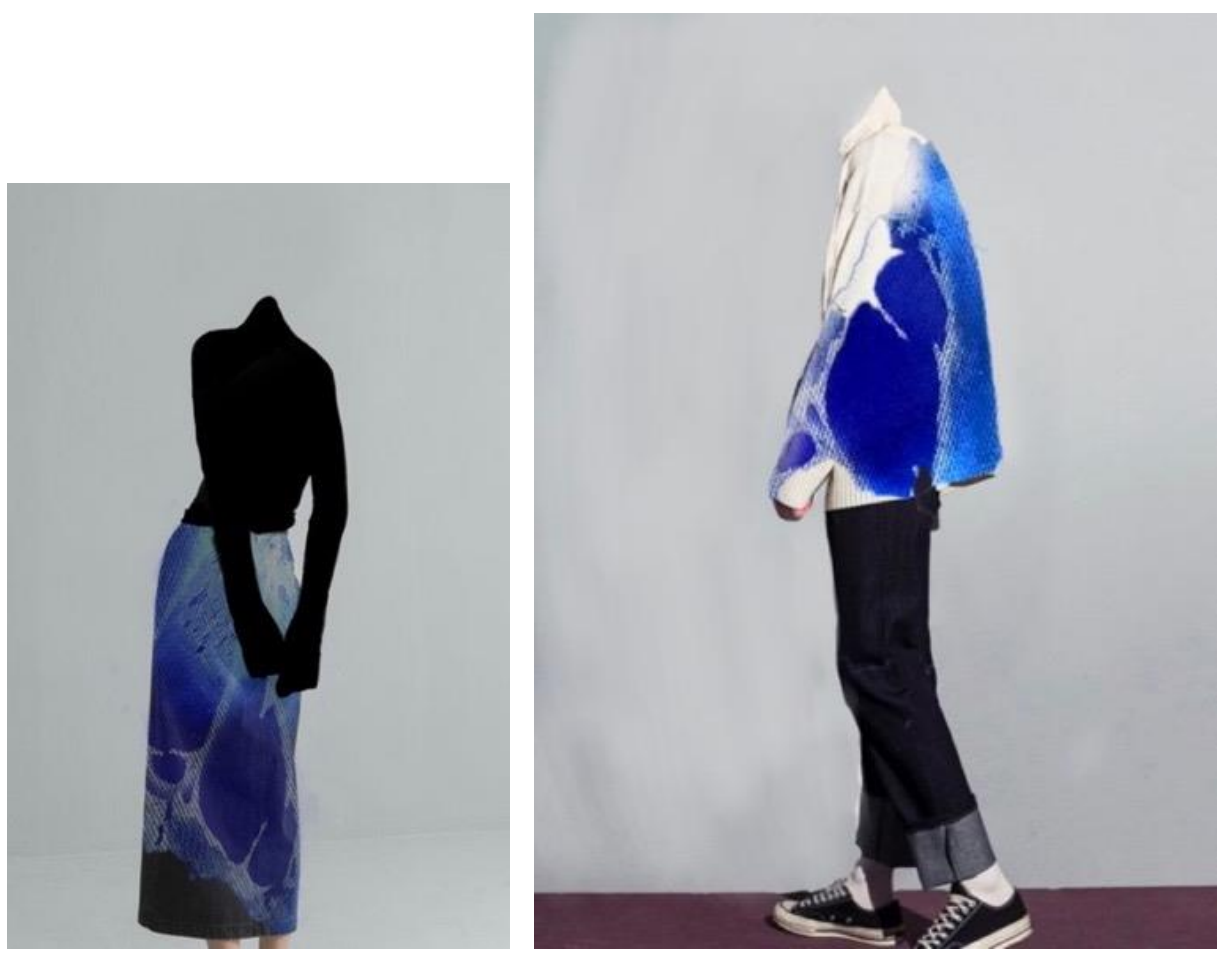

Figure 17 and 18: Implemented pattern

\subsection{Creation of repeat pattern on silk}

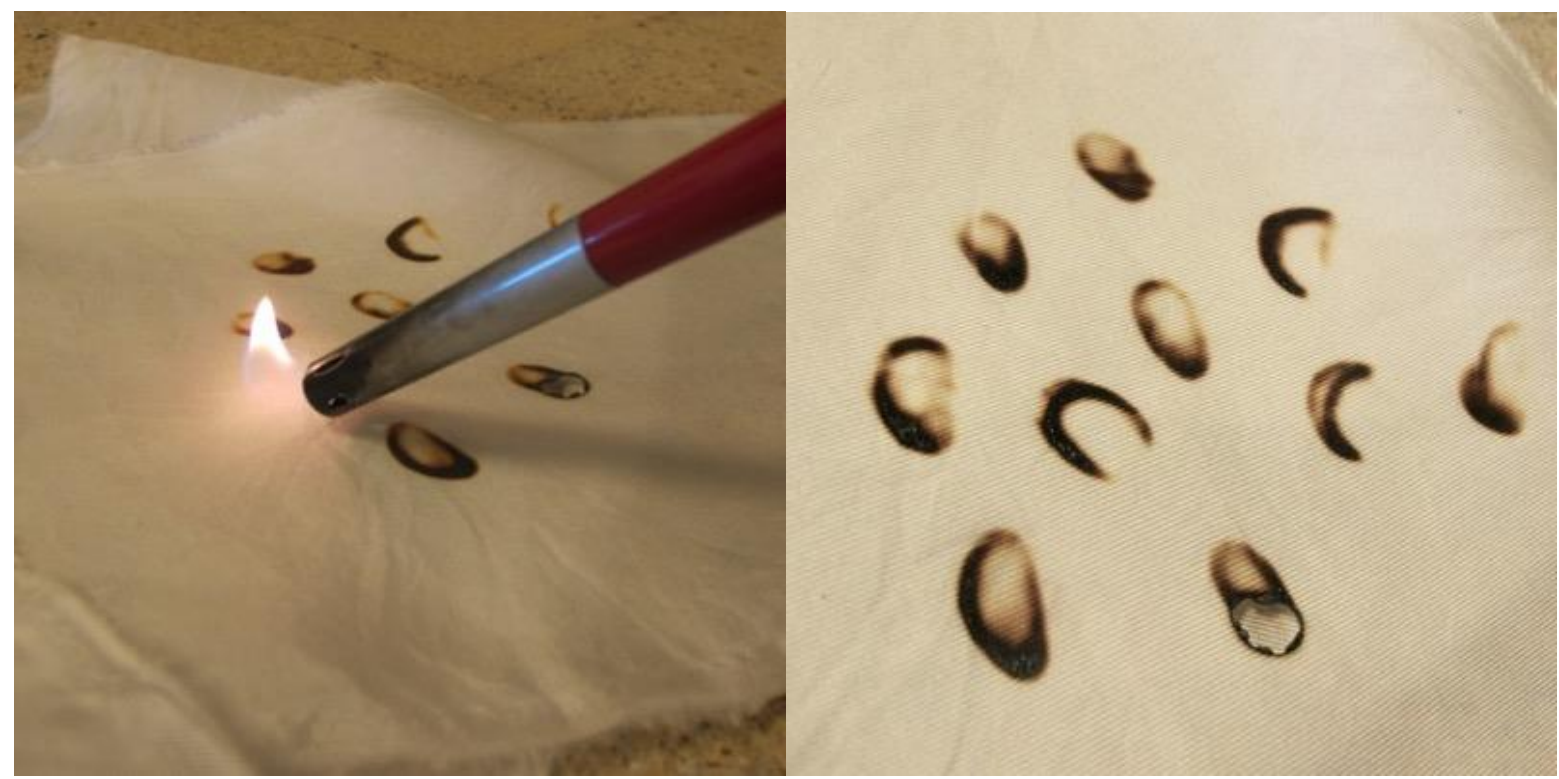

Figure 19: Burning silk test

Figure 20: Raw pattern 


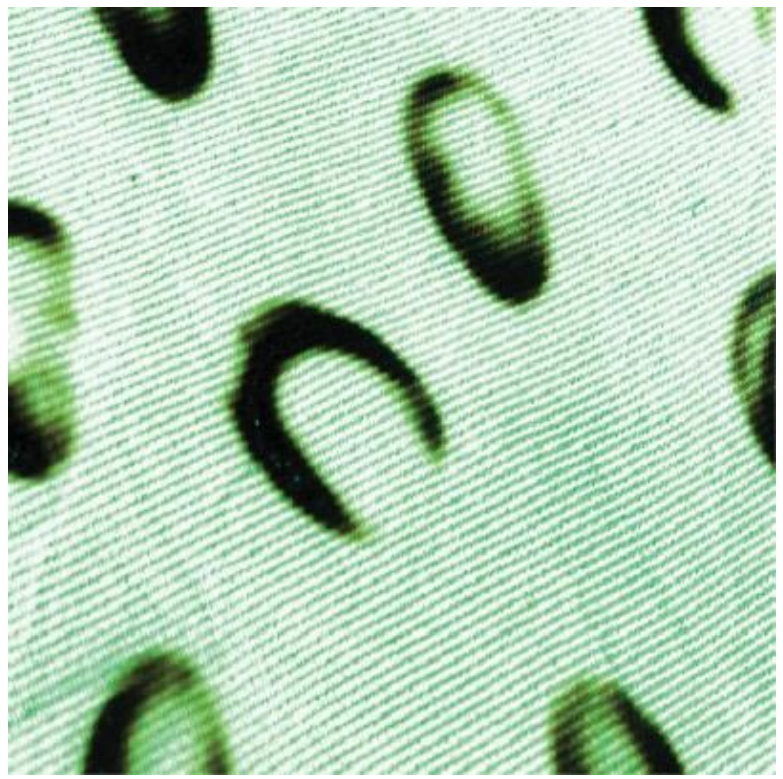

Figure 21: Isolated area

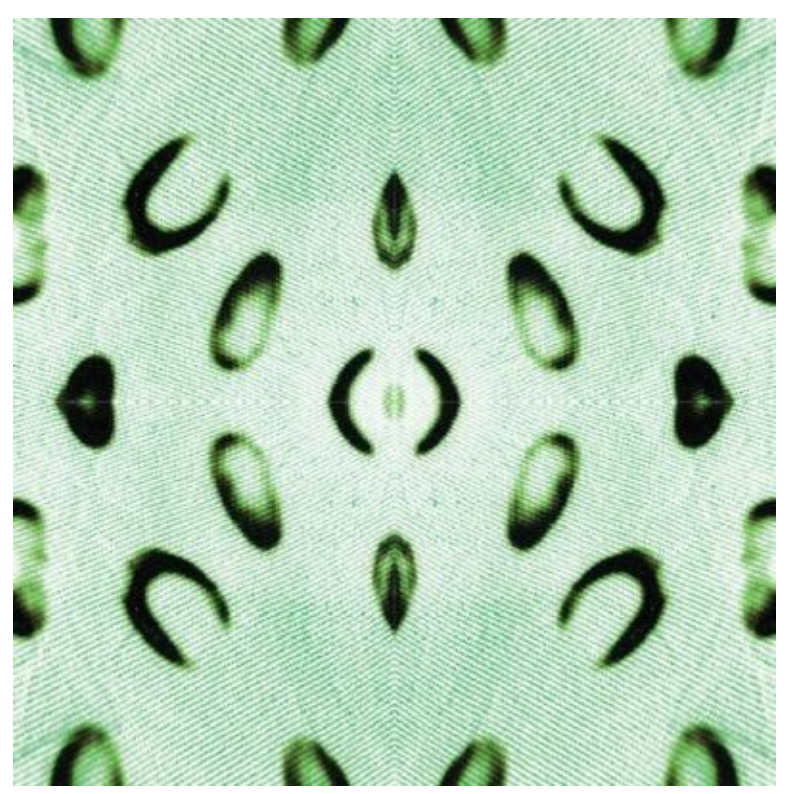

Figure 22: Area rotated 4 times, Rotation symmetry

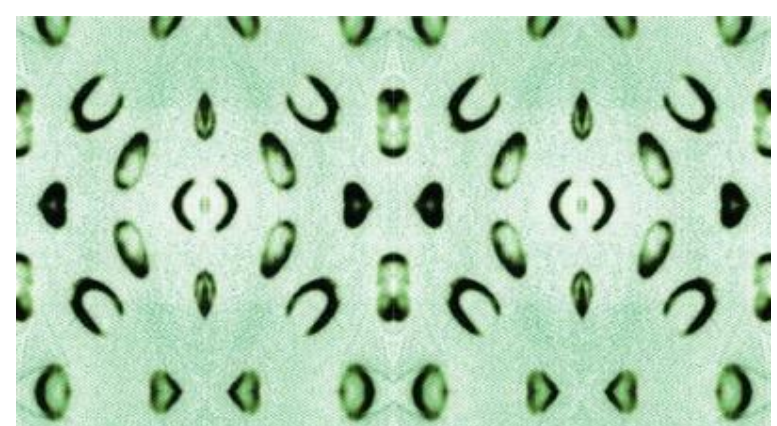

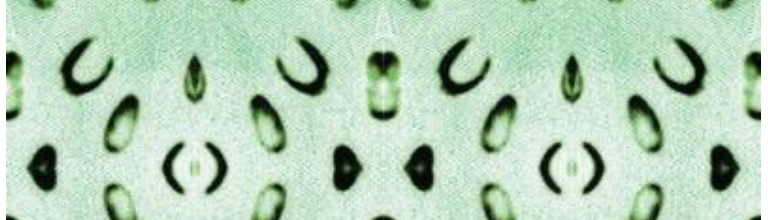
$\sin 0.6000$ A $\mathrm{n} \cap \mathrm{n}$ a $\mathrm{n}$

Figure 23: Motif repeated 16 times

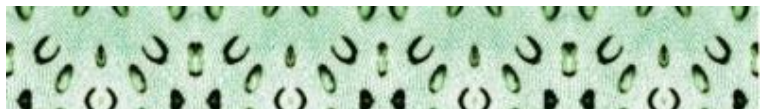

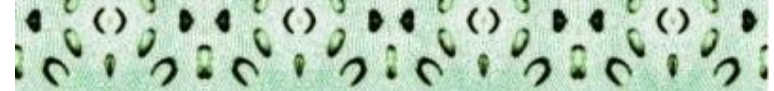
0.00000000000000

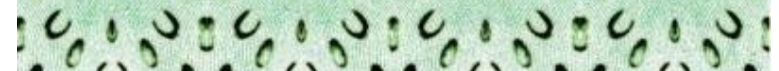

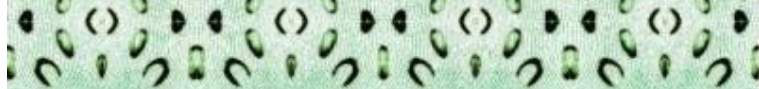
0000000000000000

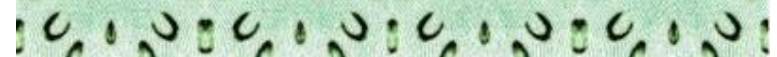

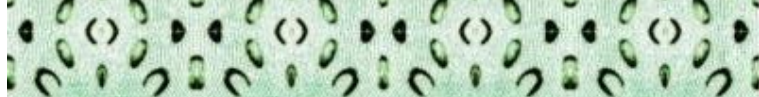
0.0000000 .000 .00

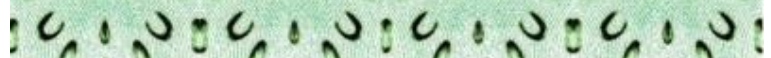

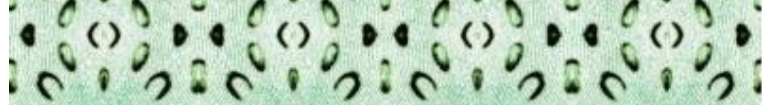
a n an a na a n a a

Figure 24: Motif repeated 64 times. 


\subsection{Creation of repeat pattern on wool}

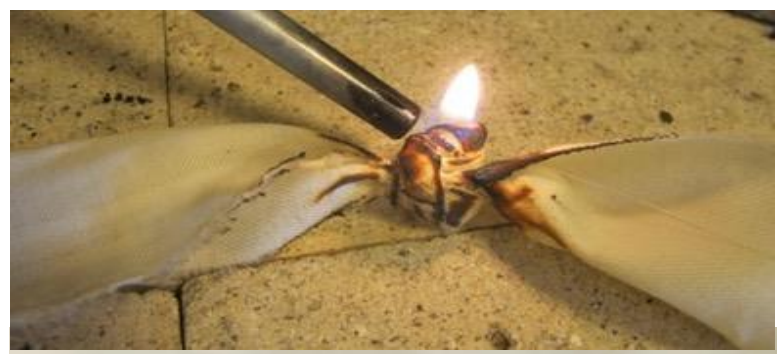

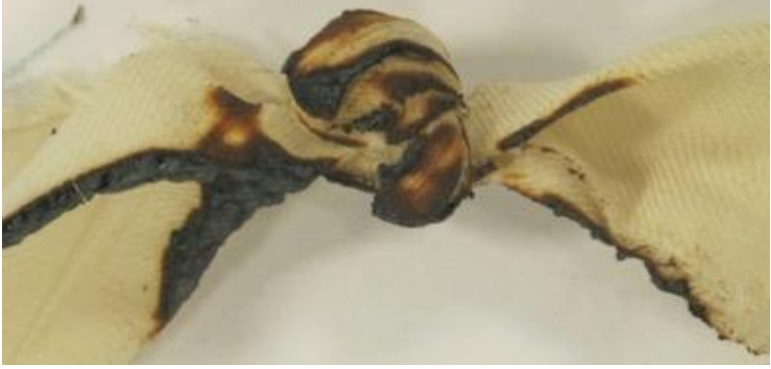

Figure 25: Wool

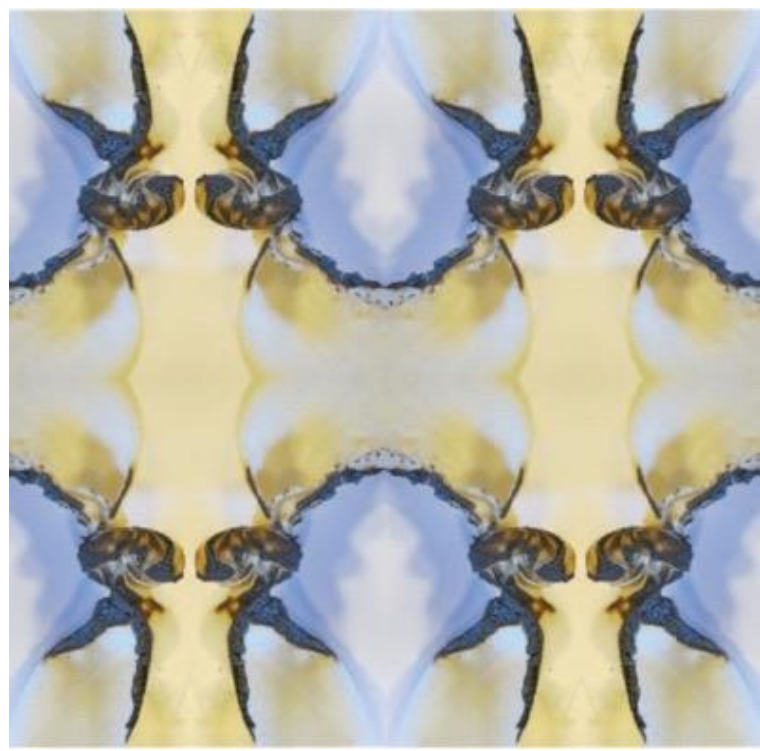

Figure 27: Motif from Fig 25, rotated 4 times

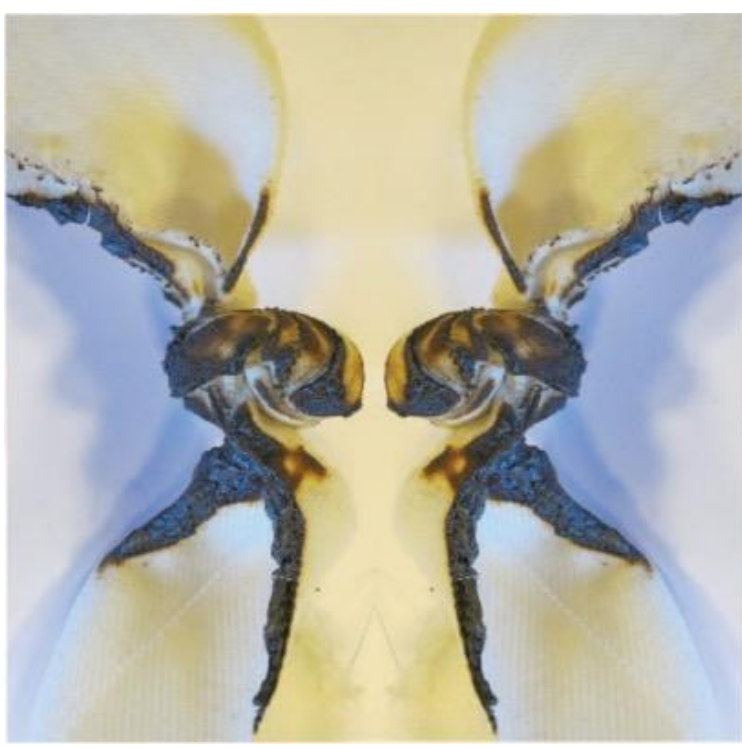

Figure 26: Motif in Photoshop mirrored vertical

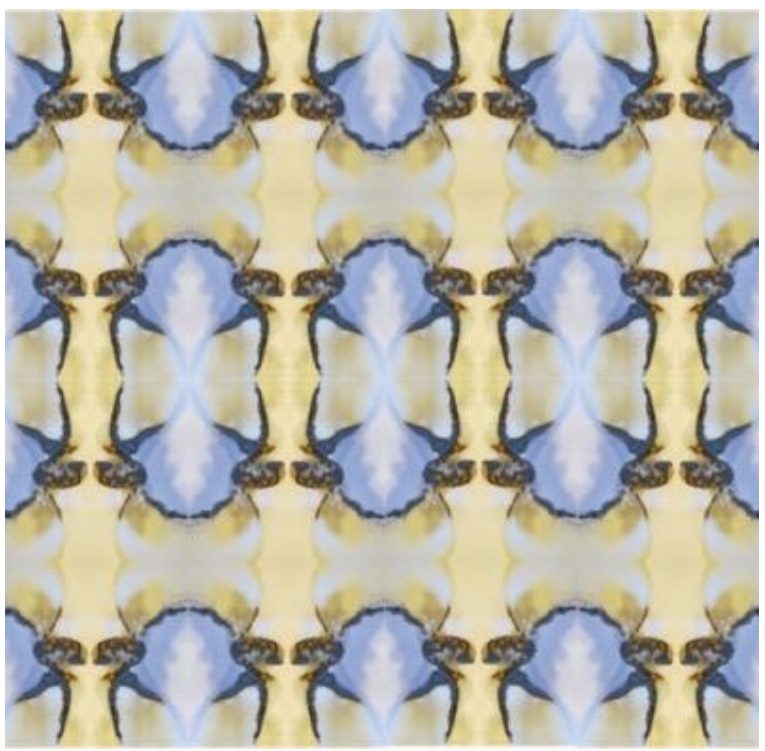

Figure 28: Motif repeated 18 times 


\section{FINAL DIGITAL PRINTEd FABRIC RESULTS}

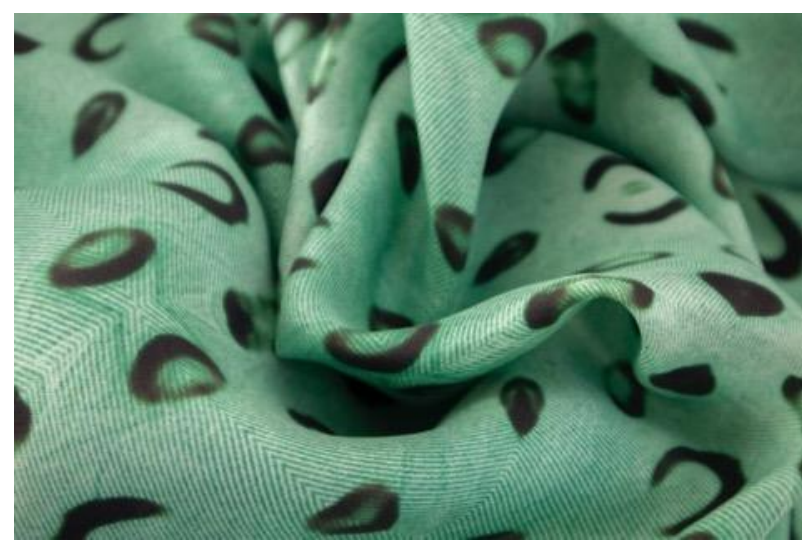

Figure 29: Green print

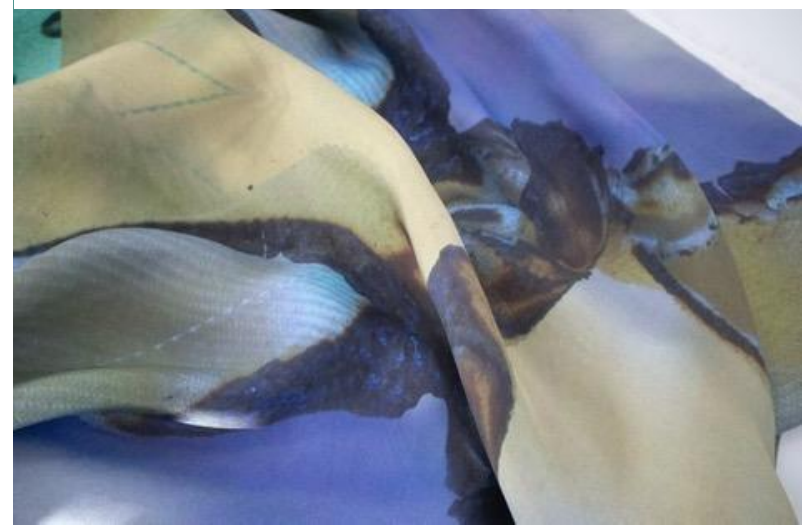

Figure 31: Burnt wool printed on silk

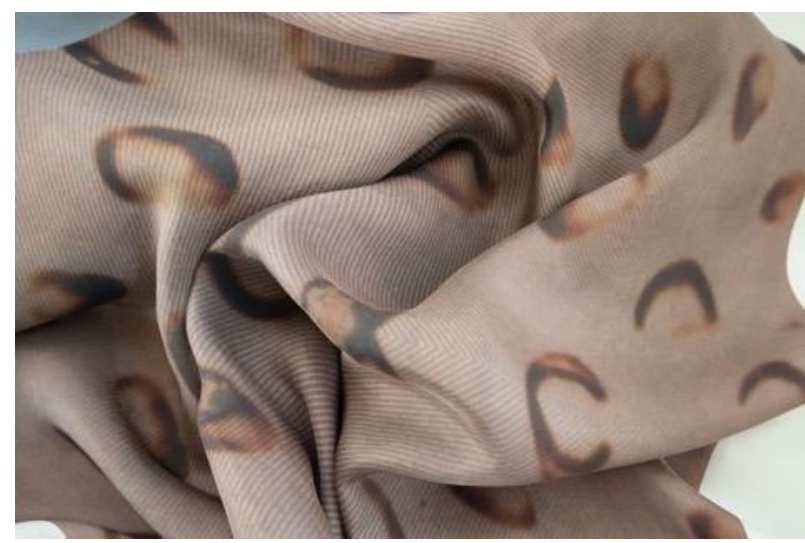

Figure 30: New colorway

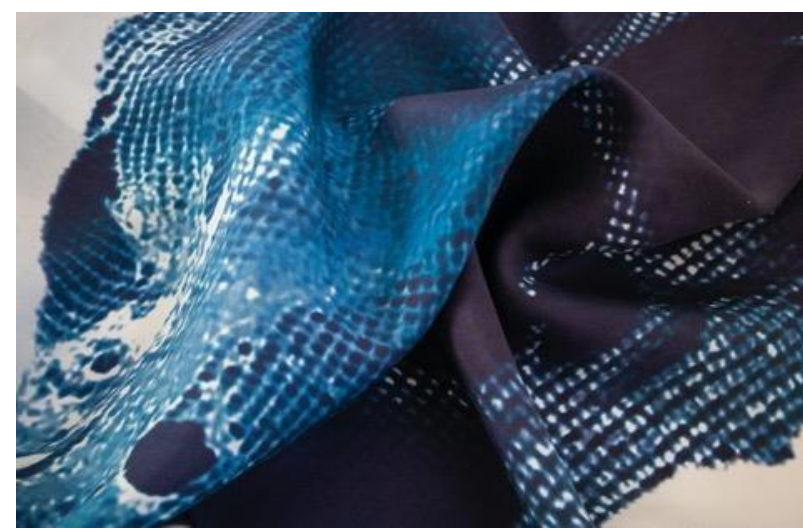

Figure 32: Student print

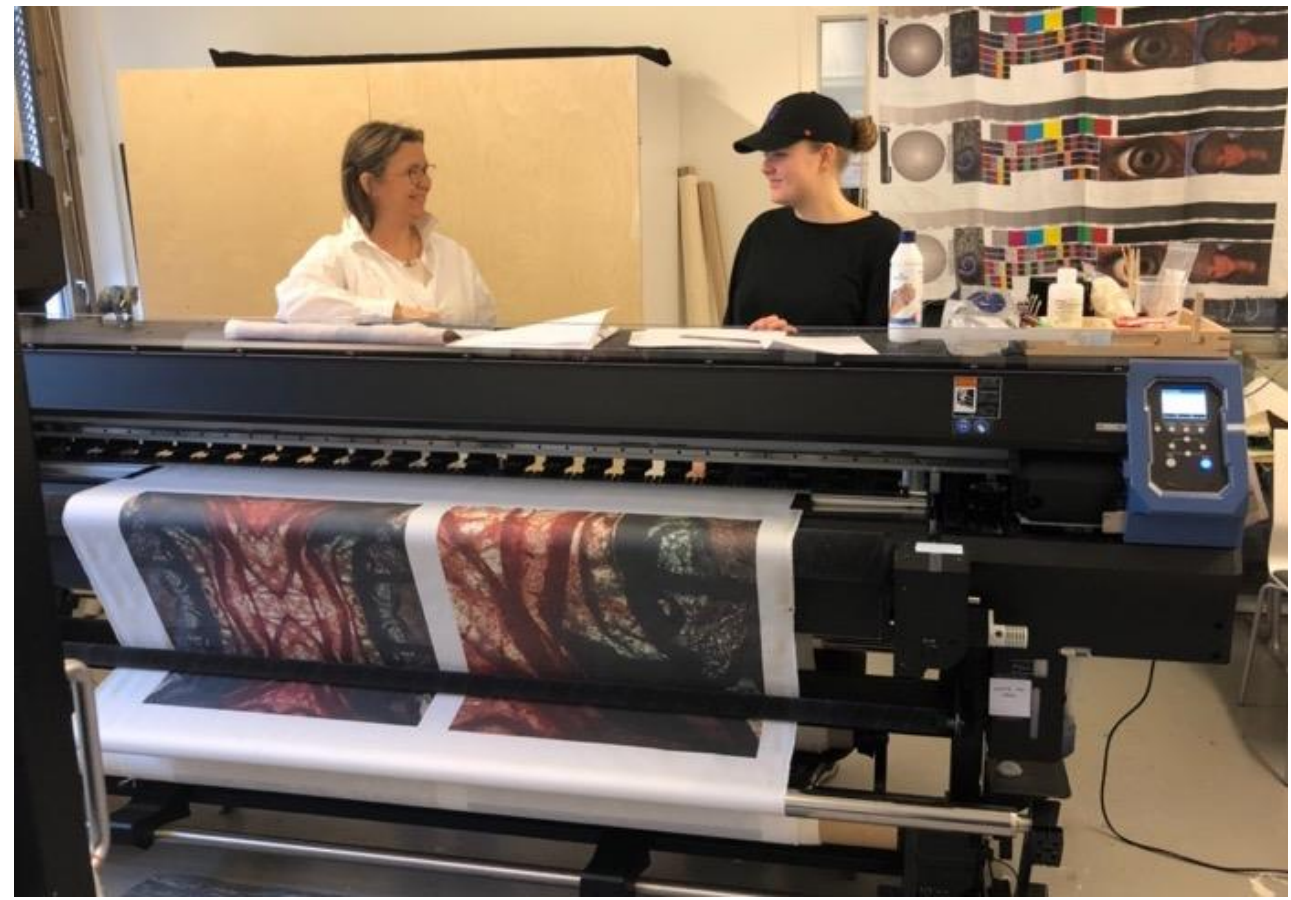

Figure 33: Tutor versus student in textile printing workshops creating superuser 


\section{CONCLUSIONS}

We learned that manual methods create unexpected design and we learn that risk taking is of great value [3]. Action driven workshops strengthen collaboration between tutor and students and future workshops should start with an outdoor workshop using forces of nature in early design processes. Working with forces of nature gave new surfaces in textiles, its uniqueness, contemporary and pure fun [4]. Unique and creative patterns riches the emotional attachment to a textile, a product whether it is customization or commercial. Creativity during a pandemic triggered playfulness and we got new insights for new methodology such as having workshops outside. Playfulness and open design processes require an ability to trust in the unknown and to be a reflective practitioner [5].

\section{REFERENCES}

[1] Norman, D. The Design of Everyday Things. 2013(Basic books)

[2] Jackson, P. How to make repeat patterns. 2020 (Laurence King Publishing Ltd, London, UK)

[3] Kelly, T and D. Creative confidence, unleashing the creative potential within us all. 2013(Crown Group, New, New York)

[4] Charny, D. The importance of being skilled, the power of making. 2011(V\&A Publishing and the Craft Council, London, UK)

[5] Schön, D. The reflective practitioners: how professional think in action. 1983(Basic books) 